beginning of training, a formal introduction to the techniques and skills of case presentation may not always occur. A well organised case conference can be a sociable, enjoyable and effective method of education in psychiatry. Conferences provide a forum for the multidisciplinary discussion of clinical cases and expose the trainee to patients, ideas and opinions they might otherwise not encounter. They are also excellent preparation for the MRCPsych examination.

Holden, N.L. (1987) Examination Techniques in Psychiatry. London: Hodder \& Stoughton.

Royal COLLEGE OF PSychiatrists (1987) Handbook for In ceptors and Trainees in Psychiatry. 23-24.

VINCENT, G.E.P. (1990) A pre-planned assessment sheet. Psychiatric Bulletin, 14, 230-232.

J.D.D. LAIDLAW and D. ALLEN, Oxford Regional Psychiatry Rotation, Campbell Centre, Milton Keynes Community NHS Trust, Muton Keynes MK6 5LD

\section{Feedback on the MRCPsych examination}

Sir: It is reassuring to hear from Dr Mann that the College takes marking the MRCPsych examination so seriously, (Psychiatric Bulletin, 1993, $17,686)$ although this results in some delay in publication of the results. However, for those candidates who are unsuccessful, feedback on the relevant portion of the examination which they failed seems to be subject to considerable delay. In my own case, which is not exceptional, I received feedback for the Spring Exam three months after publication of the results and some three weeks before the Autumn diet. Consequently this feedback, although constructive and welcomed, is of limited utility. Why the delay, and can anything be done to expedite the feedback?

JAMES WARNER, 7 Streatham Common South, London SW16 3BT

\section{Outcome measures in mental health}

Sir: In the current era of open access to patient notes, I would be very interested to discover psychiatrists' attitudes to the following matter.

I recently attended a conference on quality assurance at which Professor Wing of the College Research Unit spoke on outcome measures in mental health. One aspect which I did not hear addressed was whether patients would have access to the current rating given to them by a health care professional. With the recent emphasis on empowerment of patients, it could be argued that this is an essential piece of information; however it is also easy to see the potential damage this may cause in certain circumstances. I feel these issues should however be addressed before outcome measures become a compulsory part of our clinical life and that we should be pro-active in developing a policy in this area rather than as on many occasions re-active.

\section{J. COATES, Belfast City Hospital, Belfast BT9 7AB}

Sir: Dr Coates refers to the simple scales now being developed by the Research Unit to measure outcomes in connection with the first mental Health of the Nation target (DOH, 1993). If and when these become part of the patient record they will be subject, like the rest of the clinical record, to the provisions of the Access to Health Records Act 1990 (NHS-ME, 1991). College guidance on this has been published (1992). A College document on confidentiality is also relevant (1990).

In general, the issues raised by the scales are no different from those involved in the use of other clinical records. Information from carers should also, of course, be recorded, raising problems that are discussed in the Act and in the College commentary.

Departiment OF Health (1993) The Health of the Nation. Key Area Handbook. Mental Illness. Pp 44-45. London: DoH NHS-ME (1991) Access to Health Records Act 1990: A guide for the NHS. Health Publications Unit

ROYAL COLLEGE OF PSYCHIATRISTS (1992) Access to Health Records Act 1990. College guidance (1992) Psychiatric Bulletin, 16, 114-1 13.

- (1990) Position statement on confidentiality (1990) Psychiatric Bulletin, 14, 97-109.

JoHN WING, Director, Research Unit, Royal College of Psychiatrists, 11 Grosvenor Crescent, London SWIX 7EE

\section{Monitoring of blood pressure at a GP depot clinic}

Sir: Depot neuroleptics are often initially prescribed within a specialist setting such as in-patient or day hospital units. With increasing emphasis on community care, the burden of providing depot medication and to some extent psychiatric follow-up is being transferred to the primary health care setting. The question as to whether patients with chronic mental illness receive the same amount of screening in terms of blood pressure monitoring as those who have chronic medical illnesses requires closer scrutiny.

Eighteen patients, from a GP depot clinic, were matched for age and sex using the practice computer, with patients suffering from arthritis. A retrospective case examination for five years was performed; the number of presentations and blood pressure measurements for each period was then recorded. 